\title{
Multiple criteria decision analysis for sanitation selection in South African municipalities
}

\author{
Frances Salisbury1*, Chris Brouckaert', Dave Still² and Chris Buckley' \\ 'Pollution Research Group, University of KwaZulu-Natal, Durban 4041, South Africa \\ ${ }^{2}$ Partners in Development, PO Box 11431, Dorpspruit, 3206, South Africa
}

\begin{abstract}
A multiple criteria decision analysis (MCDA) was developed for the selection of sanitation systems. This decision support system was aimed at assisting municipal engineers to design and implement sustainable solutions to meet a municipality's obligation to provide free basic sanitation (FBS). Multi-attribute value theory (MAVT) was selected as the method most suited to the problem under consideration. Criteria which determine the sustainability of sanitation were selected from the literature and a spreadsheet-based MCDA with stakeholder and expert user interfaces was developed. Stakeholders determine the weighting of each indicator and expert users determine the values to be entered for the alternatives against each indicator. The partial values are aggregated using a weighted sum function. Research carried out into the implementation of FBS by the eThekwini Municipality that includes the city of Durban was analysed. This informed the allocation of indicator values to the sanitation alternatives under consideration: ventilated improved pit latrines (VIPs) and urine diversion dehydrating toilets (UDDTs). An innovative scenario analysis method was used to determine the effect of different weightings and/or values, representing changes in stakeholder involvement, resource recovery and political support for ecological sanitation. The MCDA was found to provide a guiding framework for municipal engineers in their efforts to implement sustainable sanitation. The process of deriving values for the MCDA is likely to prove even more useful than the overall value scores of the options under consideration.
\end{abstract}

Keywords: VIP ventilated pit latrine, UDDT urine diverting dry toilet, sustainability, eThekwini

\section{INTRODUCTION}

In South Africa, the Free Basic Sanitation policy (FBS) was developed to ensure that the country's poorest citizens have access to hygienic excreta disposal facilities (DWAF, 2003). Legislation enacted since 1994, including the Water Services Act (RSA, 1997), devolves responsibility for the provision of this service to municipalities, with infrastructure to be funded through the annual Municipal Infrastructure Grant (or, more recently, the Urban Settlements Development Grant for Metro Municipalities) and operation and maintenance through the Local Government Equitable Share.

Conventional waterborne sewerage is very successful in removing excreta from the vicinity of those producing them but it has some limitations (Panesar and Werner, 2006). Sewers require a reliable and plentiful water supply, a high level of maintenance by skilled personnel, and an effective system of treatment for the waste products (Flores et al., 2008). A system which dilutes human excreta with large amounts of potable water and then attempts to reclaim this water downstream is hard to justify in water-scarce countries (Panesar and Werner, 2006).

In South Africa, the wastewater treatment works are already under severe strain and sanitation has yet to be extended to $11 \%$ of the population (DWA, 2012). Even more ominously, there is a failure of many systems introduced in the past 20 years (Austin, 2003; DWA, 2012; Montgomery et al., 2009; Starkl et al., 2013).

A number of alternative systems have been developed for household sanitation and for the disposal of waste from these facilities (Franceys et al., 1992; Tilley et al., 2008; Wagner and Lanoix, 1958). There has been a shift to decentralised

\footnotetext{
To whom all correspondence should be addressed.

e-mail: salisburyf@gmail.com

Received 8 November 2016; accepted in revised form 13 June 2018
}

technologies deemed more appropriate for areas where water supply is less certain (Van Lier et al., 2000). Economic and environmental considerations may also favour these options.

Over a million ventilated improved pit latrines (VIPs) have been built in South Africa in the past 20 years, but a survey of water services authorities in 2009 indicated that many of these are nearly full (Still and Foxon, 2012). Urine diversion dry toilets (UDDTs) are the primary form of sanitation advocated by the ecological sanitation (Ecosan) movement (Zurbrügg and Tilley, 2009) and this technology has been introduced to South Africa in the past 15 years.

\section{Indicators of sustainability}

Sustainability depends on a range of factors, of which technology is only one. Users' acceptance of a particular option may affect their maintenance of sanitation facilities and hence the lifespan of the system (Assefa and Frostell, 2007). Money must be available when maintenance or replacement is required (Bracken et al., 2005). An adverse impact on the environment may compromise the sustainability of an otherwise attractive technology. Various frameworks have been developed to support decision makers in their efforts to provide water, sanitation and hygiene solutions and these were comprehensively reviewed by Palaniappan et al. (2008) and Olschewski and Casey (2015). Dwipayanti et al. (2017) conducted a systematic review of the literature on the provision of sustained sanitation services, with a particular focus on the IBM-WASH framework (Dreibelbis et al., 2013).

The study described in this paper was aimed at assisting municipal engineers faced with a choice between different technologies to ensure that they consider all the various dimensions of sustainability when making their decision.

In their multiple criteria approach to the assessment of decentralised wastewater technologies, Balkema et al. 
(2002) identified three sustainability dimensions: economic, environmental and socio-cultural. There are conflicts between different objectives, and hence a need for trade-offs to achieve an optimal solution. Flores et al. (2008) also described the tools used to assess the sustainability of engineered wastewater systems and found that sustainability indicators cover all three dimensions while other techniques may take only one or two dimensions into account.

Kimera et al. (2013) described the Technology Applicability Framework (TAF) tool which has been developed by the IRC (International Reference Centre for Community Water Supply and Sanitation) for the assessment of water, sanitation and hygiene (WASH) technologies. This tool has been used to inform country-based Learning Alliances in their efforts to improve the supply of sanitation, water and hygiene in subSaharan Africa (Taylor et al., 2017). The framework assesses technologies using 6 sustainability dimensions: economic; technological; social; skills and know-how; environmental; and institutional and legal. Each dimension is scored from the point of view of 3 different stakeholders: users or buyers; producers or providers and regulators, investors or facilitators. This supplies 18 indicators on which each technology is assessed. Scores are arrived at using 4 to 6 guiding questions for each indicator. Results are not aggregated but are presented as a matrix, with icons and colours used to indicate aspects of good or poor performance, as well as areas needing further clarification (Olschewski and Casey, 2015).

If the criteria which determine the sustainability of a sanitation system are to be used in decision making, they need to be assessed in some way. The literature provides numerous ways of measuring the environmental impact of sanitation, for example, life cycle analysis (LCA) (Hellström et al., 2000; Palme et al., 2005). An important role of the sanitation system is to reduce the load of organic compounds (measured for example by COD or BOD) and other elements in the excreta (e.g. $\mathrm{N}$ and $\mathrm{P}$ ) before these are released to the wider environment. Energy use should be minimised as should the water required to operate the system.

The costing of sanitation systems may be approached from the economic or the financial perspective. Some studies have taken a broad, economic approach which values the social and environmental benefits associated with appropriate management of human waste assessed using measures such as cost-benefit analysis (Hutton and Haller, 2004).

A financial costing takes into account the costs, measured directly in currency, incurred in the provision of a service (Franceys et al., 1992). For a sanitation system these extend beyond the purchase of hardware for excreta collection, storage, transport, treatment and disposal, to include community engagement and management of downstream processing (Strauss and Montangero, 2002, p. 17). Many authors choose to report costs divided into capital expenditure and cost of operation and maintenance (O\&M) (Holden et al., 2003; Hutton and Haller, 2004; Rosemarin, 2008). The IRC offers web-based life-cycle costing tools on their WASHcost site (Dickinson and Fonseca, 2014). This takes into account the cost of capital, operation expenditure, capital maintenance and the expense of supporting the technology for sustained service provision. This analysis choice might be useful to municipalities in South Africa where separate funding mechanisms provide for infrastructure and maintenance.

Quantifying social sustainability is a difficult task, particularly since there is no consensus on the definition of this dimension (Assefa and Frostell, 2007). Suggested social indicators include social justice, participation, safety, social cohesion, employment, health, equity, awareness for sustainability (Dempsey et al., 2011; Murphy, 2012). In developing a set of sustainability criteria to assess bioenergy systems, Buchholz et al. (2009) identified participation, monitoring of all criteria, compliance with laws and food security as the social criteria considered most important in a survey of experts. Other criteria, such as cultural acceptability and social cohesion were ranked as having low importance. This may reflect the gap between community concerns and those of technical experts. When a system is rated on these indicators, the scale is almost invariably a qualitative one (Bracken et al., 2005; Flores et al., 2008; Van der Vleuten-Balkema, 2003).

\section{Multiple criteria decision analysis}

The objective of multiple criteria decision analysis (MCDA) is to assist decision makers to choose the best course of action where the available options may be compared on the basis of a number of different aspects. These criteria are often conflicting, with alternatives performing well against some criteria and poorly against others (Belton and Stewart, 2002). These authors described the process of preference modelling within the MCDA system as a constructive rather than a descriptive process. During the application of the MCDA decision makers should learn more about available options, as well as gaining an understanding of the points of view of other stakeholders.

The performance of an alternative must be assessed for each criterion and these raw scores must be converted into value scores using a scale which reflects the range of possible raw scores but also reflects the value of changes in them. This is not necessarily a linear relationship since there may, for example, be thresholds below which an indicator has little impact but above which its value increases rapidly. Similarly, there may be a level above which further increases have little value. However, many authors use a linear transformation for quantitative variables (e.g. Agudelo et al., 2007; Edwards and Newman, 1982; Hajkowicz and Higgins, 2008; Loetscher, 1999).

The weighting of criteria serves to reflect the preferences of decision makers, so that more emphasis is placed on those factors that are considered more important. Edwards and Newman (1982) indicated that simple methods of weighting may provide a useful approximation of the feeling of decision makers regarding the importance of different criteria, and suggest that they may produce similar results to more complicated methods. However, Belton and Stewart (2002) point out that weights act as scaling factors in that they imply trade-offs between the value scales for different criteria. A weighting for one criterion of twice that for another criterion implies that the decision maker attaches the same value to a 1-point increase for the more heavily weighted criterion as he or she does to a 2-point increase in the other criterion.

Aggregation of the scores is carried out to arrive at an overall score $V(a)$ for each alternative $a$. This is often done using an additive function of the form

$$
V(a)=\sum_{i=1}^{m} w_{i} v_{i}(a)
$$

where $m$ criteria are used to evaluate the alternatives, $w_{i}$ represents the weighting of the $i^{\text {th }}$ criterion and $v_{i}(a)$ the marginal value of alternative $a$ for the $i^{\text {th }}$ criterion. 
Some examples of MCDA applied to sanitation include SANEX (Loetscher, 1999), WAWTTAR (Finney and Gearhart, 2004; Palaniappan et al., 2008) and SSPRA (Howard et al., 2000). Various other authors have used spreadsheet-based MCDA models to assess sanitation options. Some MCDA models use simple scales to rate alternatives for each indicator. These may be scales from 1 (poor) to 10 (good) (e.g. Wiwe, 2005) or 1 to 5 (undesirable to desirable) (De Silva, 2007; Katukiza et al., 2010; Mukuluke and Ngirane-Katashaya, 2006; von Münch, 2007). Provided all the rating scales are commensurate, these can be aggregated using weighting factors from 0 to 1 and which sum to 1 so that the final score for an alternative will be on an equivalent scale.

WhichSan is a spreadsheet-based sanitation selection program developed by Partners in Development for the Water Research Commission (Still et al., 2009). It is designed to compare on-site sanitation options with one another and with fully waterborne sewerage and was developed specifically for the South African context. The feasibility screening in SANEX is similar to the process followed by WhichSan.

\section{Sanitation projects in the eThekwini Municipality}

The eThekwini Municipality (EM) covers an area of $2297 \mathrm{~km}^{2}$ and a population of 3.5 million people in urban, peri-urban and rural settlements. The eThekwini Water and Sanitation unit (EWS) is charged with providing water and sanitation to the residents of eThekwini.

Some areas in the EM are designated as being outside the 'waterborne edge', in that they are too far from the existing network for it to be economically viable to provide residents with waterborne sewerage.

VIPs have been designated as the minimum acceptable level of basic sanitation by the South African Government (DWAF, 1996). They provide a robust sanitation solution in that they can accept a range of wastes into their pits without complete failure to function, and can be used even after the superstructure (roof, walls, door, pedestal and vent pipe) has been vandalised. The first VIP latrines were constructed in the Durban area in the 1990s. By the time the eThekwini Municipality changed its policy to offer only UDDTs, more than 45000 VIPs were in existence in the municipality. A serious concern was that pit latrines ceased to provide a sanitation solution when the pits were full, and this was occurring more rapidly than expected (Bhagwan et al., 2008). Emptying is undertaken by the municipality, at no cost to the users. In order to carry out this function efficiently, EWS made the decision to empty the pits on a planned, area by area basis rather than emptying individual pits as they become full. This will be done every 5 years.

UDDTs which have been built by EWS are designed so that urine is diverted to a soakaway and not collected for reuse. A double vault system allows faecal matter to decompose before householders need to remove it. The initial strategy was that contents would be buried on site and residents not encouraged to use any products from the UDDT in agriculture or household food production. Gounden et al. (2006) expressed concern that if the municipality emptied the vaults, there would be no incentive for residents to operate the toilets correctly. However, in 2015 EWS called for tenders for an emptying service in response to political pressure for equity between users of UDDTs and VIPs.

Gounden and Buckley (2009) reported that the UDDT construction project enjoyed local and national political support at the time of its implementation. The project improved construction skills in the community and made a contribution to local economic development. By the end of the 2010/11 financial year, 89307 UDDTs were recorded in the eThekwini Municipality. This number declined to 80083 by the end of 2012/13.

Sanitation research in the eThekwini area by the University of KwaZulu-Natal provides an insight into numerous aspects of the performance of VIPs and UDDTs.

Buckley et al. (2008) described the processes which occur in the pits of VIPs and further studies characterised fresh faeces and VIP sludge in terms of total solids (TS), organic or volatile solids (VS), total chemical oxygen demand (tCOD), ammonia and phosphates (Bakare et al., 2012; Nwaneri, 2009). Brouckaert et al. (2013) modelled the degradation processes in VIP pits to arrive at an estimate of filling times.

Lutchminarayan et al. (2007) studied the health benefits of the installation of UDDTs in eThekwini while Buckley et al. (2008) examined the risk associated with emptying UDDT vaults. Velkushanova (2013) presented an analysis of faecal sludge from UDDTs in eThekwini.

Various studies have investigated user attitudes to on-site sanitation and found widespread dissatisfaction (Duncker et al., 2006; Maharaj, 2012; Narsai et al., 2013; Roma et al., 2013). Both Maharaj (2012) and Mnguni et al. (2008) found users reluctant to empty vaults. UDDTs have been seen as unhygienic and hazardous to residents' health, or even as a 'punishment' for poorer people (Maharaj, 2012).

The aim of this research was to analyse the course and outcomes of the large-scale decentralised sanitation projects carried out by the eThekwini Municipality in the framework of a decision support system (DSS) and to assess whether this DSS would allow municipal engineers to compare a range of sanitation options, and to select the one most suitable for their situation (Salisbury, 2015).

\section{METHODOLOGY}

WhichSan, the program developed by Partners in Development (Still et al., 2009) provides a feasibility assessment and costing for sanitation systems in a South African context. The concept of sustainability was the basis for a further MCDA, using criteria derived from the literature (Agudelo et al., 2007; Bracken et al., 2005; Cotton and Saywell, 1998; Flores et al., 2008; Muga and Mihelcic, 2008; Van der Vleuten-Balkema, 2003).

These criteria were organised into a hierarchy or 'value tree', consisting of a number of levels having progressively more subcriteria at each level. At the first level, the criteria encompass the broad areas of concern for decision makers: health, technology, environment, socio-culture and the economy. The last level of the hierarchy, or 'leaves' of the tree, consists of criteria which allow alternatives to be assessed or ranked in an unambiguous way (Belton and Stewart, 2002). Initially a comprehensive list of criteria was compiled (see Fig. 1). The shaded criteria are those which are assessed by WhichSan.

The list of criteria produced was too extensive to be incorporated into a meaningful MCDA because the effect of each criterion becomes too diluted, and there is a danger of user fatigue. Loetscher (1999) used 32 indicators under 2 principal headings, but he used a range of amalgamation methods in an effort to avoid the excessive diminution of the effect of individual criteria.

The need to reduce the number of criteria was balanced against the need to consider as many aspects of the issue as possible. Careful consideration was given to the peculiarities 


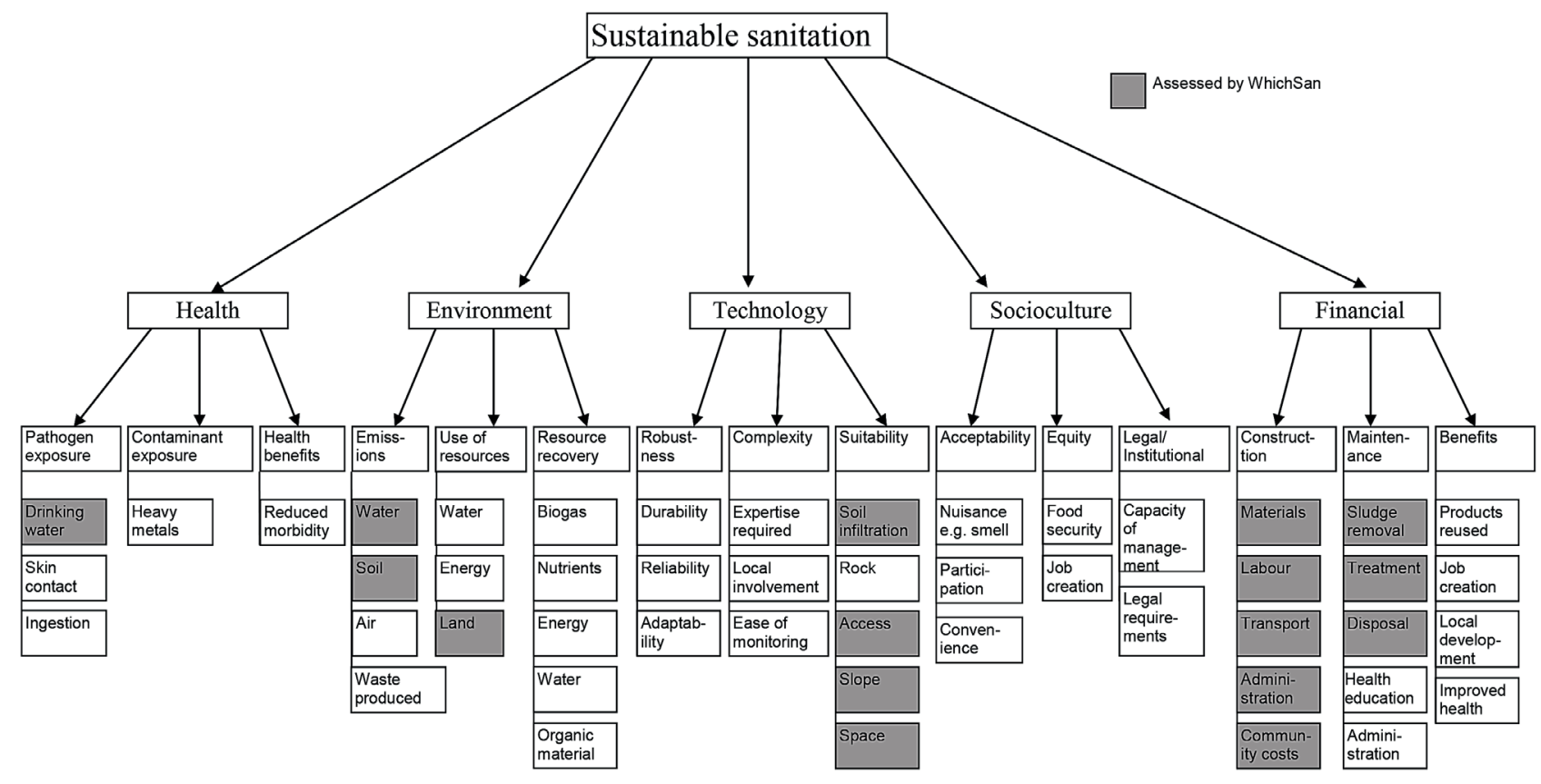

Figure 1

Value tree for assessing the sustainability of sanitation systems

of the South African situation, such as the application of the Free Basic Sanitation policy. Since this MCDA is designed to be used with WhichSan, some important criteria were eliminated since they would be considered in the feasibility stage of the assessment. Some criteria were eliminated because they were redundant. For example, the largest source of $\mathrm{CO}_{2}$ is likely be the energy source for the system and hence carbon emissions are not interrogated specifically but net energy requirement is included. Other criteria were combined: water use and water recovery in net water requirement and similarly energy use and recovery in net energy requirement.

Although WhichSan includes a full costing for the sanitation options under consideration, the financial criteria for capital expenditure and operations and maintenance were retained, since the aim of the MCDA is to obtain a balanced assessment and cost is always an important consideration.

This rationalisation process reduced the list to 23 criteria (see Table 1). Of these, 8 are environmental, 7 socio-cultural, 1 health, 4 financial and 3 technological. In order to avoid a situation where the weightings of the overall criteria give undue weight to a few sub-criteria, the criterion of reducing contact with faeces was included in the 'Socio-cultural' grouping since it is a cultural as well as a health issue.

Since the nature of the technology and the cost of its implementation are closely linked, it was decided to group these two concepts together, to create the overall criterion 'Finance and Technology' with 7 sub-criteria. 'Environmental', with 8 sub-criteria, formed a third category.

These three groupings reflect the so-called three pillars or dimensions of sustainable development: social, economic and environmental (Assefa and Frostell, 2007).

The division of the criteria into these three groups might also be expected to reflect three possible groupings of stakeholders in the South African Free Basic Sanitation scenario: the wider community, concerned with the environmental impact of the system; the municipality and municipal engineers, concerned with the costs of construction and maintenance and life span of the intervention; and the users, concerned with comfort, privacy, and other sociological issues.

The indicators chosen for the MCDA were a mixture of quantitative and qualitative measures. Environmental criteria could be measured quantitatively, while financial and technological criteria were divided between quantitative and qualitative indicators, and the socio-cultural indicators were all qualitative. The indicators are listed in Table 1.

The simple linear normalisation function recommended by Edwards and Newman (1982) was used for quantitative indicators. The value scores ranged from 0 to 5 , to maintain consistency with those developed for the WhichSan program. If a larger value is better, the normalisation function is represented by Eq. 2, and if lower is better (e.g. cost or net energy), Eq. 3 is applied. Raw scores are rounded to the nearest integer and these are scaled to value scores between 0 and 5 , shown to 2 decimal places in the MCDA.

$$
\begin{gathered}
v_{j}=5 \frac{x_{j}-x_{\min }}{x_{\max }-x_{\min }} \\
v_{j}=5 \frac{x_{\max }-x_{j}}{x_{\max }-x_{\min }}
\end{gathered}
$$

where $x_{j}$ is the raw score of option $j, x_{\max }$ is the largest reasonable value for the raw score, $x_{\min }$ is the smallest reasonable value for the raw score and $v_{j}$ is the value on a scale of $0-5$ which is entered into the matrix.

Qualitative indicators are on a scale of 1 to 5 . In describing the different levels an attempt was made to make the underlying rationale for including the criterion explicit. As an example, the criterion 'Requirement for outside intervention' was described by the scale: 0 : monthly intervention, 1: 6-monthly intervention, 2 : 
annual intervention, 3: intervention every 2 years, 4 : intervention every 5 years, 5 : intervention every 10 years or more. The numbers are simply there to make it easier to assign a value to an option than for terms such as 'frequent' or 'seldom', and are not intended as exact numerical measures. There would be no non-integer values assigned and a process of approximation would assign values to different systems. For purely qualitative variables, the scale was developed to guide the user in scoring an alternative, with descriptions of the different levels of performance.

A multi-attribute value function (MAVF) was constructed to aggregate the scores of a sanitation option to give a final score or index, in the process applying weightings to each component value score according to the preferences of the decision makers or stakeholders involved. The indices or overall value scores thus calculated for different options allow comparisons and ranking of alternatives. Microsoft Excel was used to perform the calculations of the MCDA. The values to be entered by the non-expert user are captured in dialogue boxes created in the spreadsheet using Visual Basic.

The weighting of the different criteria is performed at two levels. Initially, the three main criteria, 'Environment', 'Finance and technology', and 'Socio-cultural' are weighted against each other. These weightings must sum to $100 \%$ and the user is prompted to adjust the values if this requirement is not met. Once this process is complete, the user enters weightings for the sub-criteria.

The matrix of values initially entered in the spreadsheet was for the two sanitation options (VIP and UDDT) and the 23 selected criteria. The Microsoft Excel workbook developed for the MCDA allows the expert user to add a further three sanitation systems and to enter values for any one or combination of these for the purposes of comparison.

The scores allocated to the two different sanitation alternatives are summarised in Table 1 . The scores were informed by the research done in the eThekwini area and are

\begin{tabular}{|c|c|c|c|}
\hline \multicolumn{4}{|c|}{$\begin{array}{c}\text { TABLE } 1 \\
\text { Final list of criteria used in the MCDA }\end{array}$} \\
\hline \multirow{2}{*}{ Criterion } & \multirow{2}{*}{$\begin{array}{l}\text { Chosen indicator } \\
\text { (min-max) }\end{array}$} & \multicolumn{2}{|c|}{ Scores for options } \\
\hline & & VIP & UDDT \\
\hline \multicolumn{4}{|l|}{ Environmental indicators } \\
\hline Efficiency of reduction in VS & $\%$ removal $(0-100)$ & $65 \%$ & $55 \%$ \\
\hline Efficiency of removal of $\mathrm{N}$ & $\%$ removal $(0-100)$ & $75 \%$ & $95 \%$ \\
\hline Efficiency of removal of $\mathrm{P}$ & $\%$ removal $(0-100)$ & $12 \%$ & $95 \%$ \\
\hline Efficiency of reduction in COD & $\%$ removal $(0-100)$ & $75 \%$ & $45 \%$ \\
\hline Energy required less energy recovered & $\mathrm{MJ} \cdot$ person $^{-1} \cdot \mathrm{yr}^{-1}(0-30)$ & 0 & 0 \\
\hline Water required less water recovered & $\mathrm{m}^{3} \cdot$ person $^{-1} \cdot \mathrm{yr}^{-1}(0-40)$ & 0 & 0 \\
\hline Nutrients recovered & $\mathrm{kg} \mathrm{N}+\mathrm{P}+\mathrm{K} \cdot$ person $^{-1} \cdot \mathrm{yr}^{-1}(0-5)$ & 0 & 0 \\
\hline Organic material recovered & $\mathrm{kg} \mathrm{DM} \cdot$ person $^{-1} \cdot \mathrm{yr}^{-1}(0-10)$ & 0 & 0 \\
\hline \multicolumn{4}{|l|}{ Financial/technical indicators } \\
\hline $\begin{array}{l}\text { Robustness: ability to withstand abuse, ease of construction, } \\
\text { simplicity of design }\end{array}$ & Qualitative & 5 & 3 \\
\hline Requirement for outside intervention, requirement for monitoring & Qualitative & 4 & 2 \\
\hline Durability: life expectancy of system & Years & 20 & 20 \\
\hline Construction cost: materials, labour, institutional requirements & $\mathrm{ZAR} \cdot \mathrm{hh}^{-1}(500-15000)$ & 6000 & 7500 \\
\hline Cost of O\&M: repairs, servicing & ZAR.person ${ }^{-1} \cdot \mathrm{yr}^{-1}(0-1200)$ & 150 & 50 \\
\hline Employment: jobs created by construction and maintenance & Qualitative & 1 & 2 \\
\hline $\begin{array}{l}\text { Local development: promotion of local business in construction and } \\
\text { maintenance }\end{array}$ & Qualitative & 4 & 4 \\
\hline \multicolumn{4}{|l|}{ Socio-cultural indicators } \\
\hline Acceptability: user perceptions of fitness for purpose & Qualitative & 3 & 2 \\
\hline Convenience: provision of sanitation where users require it & Qualitative & 3 & 3 \\
\hline Equity: fulfilment of requirements of all gender and income groups & Qualitative & 3 & 3 \\
\hline Legal/institutional: fit with legal requirements, institutional support & Qualitative & 4 & 4 \\
\hline $\begin{array}{l}\text { Facility for ongoing hygiene education: commitment of government } \\
\text { to fund }\end{array}$ & Qualitative & 4 & 4 \\
\hline Participation: facility for user involvement & Qualitative & 4 & 4 \\
\hline Food security: contribution of system to household-based food production & Qualitative & 0 & 0 \\
\hline Pathogen exposure & Qualitative & 4 & 1 \\
\hline
\end{tabular}


specific to those circumstances. For example, the burial of UDDT waste on-site means that this system requires no energy (0 MJ.person ${ }^{-1} \cdot \mathrm{yr}^{-1}$, giving a value score of 5 in the MCDA), but also scores 0 for nutrient recycling.

It was considered to be beyond the scope of this study to develop a system for the elicitation of weights from stakeholders in a way that would satisfy the requirement for trade-offs between criteria. Furthermore, rather than changing the criterion weights systematically, to produce hundreds of different combinations, or developing a probability distribution for the overall ratings, a scenario approach was used.

This bears some similarity to the approach of Stewart et al. (2013), which combines MCDA with scenario planning, but rather than use the scenarios (abbreviated to $S_{j}$ ) in place of specific technology alternatives, the alternatives are retained and different combinations of weights reflect different stakeholder scenarios. In further scenarios, not only weights but also indicator values are varied in order to mimic performance under different circumstances.

In each scenario above, the altered scores for VIPs and UDDTs were recorded.

\section{RESULTS}

It is important to note that the scenarios presented here are only intended to demonstrate how a municipal engineer might use the MCDA, not to give definitive answers to the relative value of VIPs and UDDTs in any situation. After a baseline scenario $\left(S_{0}\right)$ was established, 4 scenarios were proposed which involved only the changing of weights for various criteria $\left(S_{1}\right.$ to $S_{4}$ ). Further scenarios involved changes to both the weightings of the criteria and the value scores of the alternatives $\left(S_{5}\right.$ to $\left.S_{11}\right)$.

\section{$S_{0}:$ Baseline scenario}

Initially, all weightings were set to the same value. Under these circumstances, the overall values or scores for the VIP and UDDT were 3.13 and 2.95, respectively. This supports the observation by Flores et al. (2008) that there is not a great deal of difference between the two systems in the eThekwini situation.

\section{$S_{1}:$ Major constraints energy and water}

A situation was considered where the important issues for the environment were that water use and energy use were low. This might be where sanitation is needed at a fairly remote location where there is no electricity or piped water.

These two sub-criteria therefore carried a weighting of $40 \%$ each. The remaining $20 \%$ within the environmental grouping carried weights of 5\%, except for the recovery criteria which were given a zero weighting. The resulting scores are 3.76 for VIPs and 3.50 for UDDTs.

\section{$S_{2}$ and $S_{3}$ : Ecosan imperative: recycling is crucial}

If it is considered essential that nutrients are recycled, the criteria for nutrient and organic matter will be given more weight. These were therefore weighted at $30 \%$. The water and energy criteria were given a weight of $10 \%$ each and the remaining four sub-criteria 5\%. The MCDA was run with equal weightings for the three main criteria $\left(S_{2}\right)$ and then again with a 40/20/40 split for environment/finance/socio-cultural weightings to mimic a situation where external funding might supplement the municipality's contribution and hence lessen the importance of financial considerations $\left(S_{3}\right)$.

Not surprisingly, the two sanitation options considered under the eThekwini circumstances do not perform well with these constraints since nutrients are not recycled. VIPs and UDDTs score 2.76 and 2.50, respectively, in $S_{2}$ and 2.60 and 2.37 in $S_{3}$.

\section{$S_{4}:$ People over environment}

This represented a situation where the political impact is significant and the project is seen as succeeding or failing on the factors which concern the recipient community. The weighting of the socio-cultural criterion was set to $60 \%$, environment to $10 \%$ and financial/technical to $30 \%$. The performance of VIPs is improved over the baseline equal weighting scenario, but only to a score of 3.22, while the overall rating for UDDTs dropped to 2.83 .

\section{$S_{5}, S_{6}$ : Excreta from UDDT reused at household level}

When the potential for nutrient reuse which is inherent in the design of UDDTs was realised, this changed the value scores for the UDDT alternative from the minimum to the maximum score for nutrient and organic matter recovery. This improved the rating of the UDDT to $3.36\left(S_{5}\right)$.

It is unlikely that if excreta were reused these would be the only values that would change. In $S_{6}$, the weightings for removal of VS, N, P and COD were changed to zero where nutrients are recycled. If this was not the case, their values would have to be changed to take into account any removal taking place in the agricultural system attached to the sanitation system rather than the system itself. It was assumed that the requirements for energy and water were still important criteria. Here the rating of the UDDT system increased still further, to $3.59\left(S_{6}\right)$.

\section{$S_{7}$ Excreta from UDDT reused with changes to socio-cultural values}

It could be assumed that the user acceptance of UDDTs would be high if nutrients were recovered and used on-site. $S_{7}$ therefore assumes that environmental values and ratings remain as they are in $S_{6}$, but in addition the user acceptance is increased to 5 and food security is increased to 4 , since the condition 'Products used at household level without institutional support.' is met.

This increases the final rating for UDDTs to 3.88 .

\section{$S_{8}$ Municipal emptying of UDDTs}

An alternative to the operation of UDDTs by users would be the emptying of UDDTs by contractors engaged by the municipality $\left(S_{8}\right)$. Maintenance costs would increase since emptying every 2 years would add approximately ZAR500.UDDT ${ }^{-1} \cdot \mathrm{yr}^{-1}$, or ZAR100. person $^{-1} \cdot \mathrm{yr}^{-1}$ for a household of 5 . If the vault contents were not disposed of on-site, energy use would be increased by the need for transportation and processing in a facility such as the black soldier fly larvae plant currently being trialled by EWS. Food security as described in the MCDA would not be improved but household contact with faeces would be reduced.

$S_{8}$ resulted in a score of 3.04 for UDDT.

\section{$S_{9}, S_{10}:$ Alternatives to on-site disposal of sludge from VIPS}

$S_{9}$ and $S_{10}$ were tested to explore the possibility of using the MCDA to take different sludge disposal options into account for 
VIP sludge. Many municipalities are likely to process sludge at their wastewater treatment works (WWTW). In this scenario, energy use would be increased significantly over on-site burial, due to the need to transport the sludge and for other processes in the WWTW. Operations and maintenance costs would also rise. Nitrogen and phosphorus removal would be improved. The values for these sub-criteria were therefore adjusted $\left(S_{9}\right)$. eThekwini is using the LaDePa machine to process sludge (Harrison and Wilson, 2012). This requires an increase in net energy requirement and operation and maintenance costs over the baseline but improves all environmental variables $\left(S_{10}\right)$.

The resulting score for VIPs with weightings equal across all criteria was 3.11 for WWTW disposal $\left(S_{9}\right.$ and 3.22 for LaDePa disposal.

\section{$S_{11}:$ Urban resistance to on-site systems}

VIPs are well-established, robust systems used by rural households for hundreds of years but under urban conditions their performance may be poorer. User acceptance is lower where those close by have flush lavatories, and political opposition might also be brought to bear on the situation. The addition of solid waste to the pits shortens their useful life. If flooding occurs, pathogen risk to residents and the risk of contamination of water become greater.

In $S_{11}$, the values for some of the socio-cultural sub-criteria were adjusted. The values for acceptability were reduced for both UDDTs and VIPs. The legal/institutional fit sub-criterion was given a lower value for both systems due to the political support component of this indicator. Community participation was scored at 1 rather than 4 for both alternatives. Furthermore, the socio-cultural criterion was weighted $60 \%$ against $20 \%$ for each of the other two main criteria since socio-cultural forces might be thought to carry more weight in a politicised situation. The resultant rating for VIPs is 2.53 and for UDDTs 2.29 .

\section{DISCUSSION}

With a 'balanced scorecard' and equal weightings for the three main criteria (Environment, Finance and Technology and Socio-cultural), the performance of VIPs in the MCDA was marginally better than that of UDDTs. This difference would have been insufficient for a decision to be made using the results but should prompt further investigation of the motivation for one or the other option.

The various scenarios and the inputs to the MCDA are summarised in Table 2 . The changes in weightings were intended to investigate the movement of scores from the baseline and the relative changes in the values for the two technologies rather than to provide any precise values for the two technology options.

Because the changes from the baseline were intended to show tendencies rather than precise values, the decision, for example, to give weights of $10 \%, 30 \%$ and $60 \%$ for environment, finance/technical and sociocultural, respectively, was to demonstrate the effect of a situation where political concerns dominate. $15 \%, 25 \%$ and $60 \%$ would show the same tendency and would have demonstrated the principle as well.

In the case of the eThekwini Municipality, a very strong driver for the change was to avoid the need to empty pits. If this were only a financial consideration, it would probably not be justified in the light of the results of this MCDA. However, the concerns of the municipality were not only financial but included the risks to the health of pit emptiers and the difficulties encountered in transporting and disposing of pit latrine sludge when it was found that the shock loading affected the operation of the WWTW (Buckley et al., 2008). There is potential for UDDTs to improve food security if the barriers to user acceptance and health risks are overcome.

Even without nutrient recovery, annual emptying of UDDTs by the municipality improves the rating of this option

\begin{tabular}{|c|c|c|c|}
\hline \multicolumn{4}{|r|}{$\begin{array}{l}\text { TABLE } 2 \\
\text { Summary of results }\end{array}$} \\
\hline$S_{n}$ & VIP & UDDT & Brief description \\
\hline 0 & 3.13 & 2.95 & Equal weightings, no nutrient recovery, contents buried on-site \\
\hline 1 & 3.76 & 3.50 & $\begin{array}{l}\text { Environmental sub-criteria weightings changed from baseline: net water } 40 \% \text {, net } \\
\text { energy } 40 \% \text {, nutrient removal } 5 \% \text { each, recovery } 0 \%\end{array}$ \\
\hline 2 & 2.76 & 2.50 & $\begin{array}{l}\text { Environmental sub-criteria weightings changed from baseline: net water and energy, } \\
10 \% \text { each, nutrient recovery } 30 \% \text { each, nutrient removal 5\% }\end{array}$ \\
\hline 3 & 2.60 & 2.37 & $\begin{array}{l}\text { As } S_{2} \text { but main categories weighted environment: finance/technical: sociocultural } 40 \% \\
: 20 \%: 40 \%\end{array}$ \\
\hline 4 & 3.22 & 2.83 & Main categories weighted environment: finance/technical: sociocultural 10\%: $30 \%: 60 \%$ \\
\hline 5 & 3.13 & 3.36 & UDDT nutrient recovery values $5 \mathrm{~kg} \mathrm{~N}+\mathrm{P}+\mathrm{K}, 10 \mathrm{~kg}$ organic matter \\
\hline 6 & --- & 3.59 & $\begin{array}{l}\text { As } S_{5} \text { but environmental weightings changed, removal values to } 0 \% \text { and other } 4 \text { criteria } \\
\text { to } 25 \% \text { each }\end{array}$ \\
\hline 7 & --- & 3.88 & As $\mathrm{S}_{6}$ but food security score increased to 4 and user acceptance to 5 \\
\hline 8 & --- & 3.04 & $\begin{array}{l}\text { Energy use increased to } 15 \mathrm{MJ} \cdot \text { person }^{-1} \cdot \mathrm{yr}^{-1} \text { and O\&M to ZAR150 } \text { person }^{-1} \cdot \mathrm{yr}^{-1} \text {, user } \\
\text { acceptance increased, contact with faeces reduced for UDDTs }\end{array}$ \\
\hline 9 & 3.11 & -_- & Increased energy use and O\&M costs, improved removal rates \\
\hline 10 & 3.22 & -- & $\begin{array}{l}\text { Energy use increased to } 15 \mathrm{MJ} \cdot \mathrm{person}^{-1} \cdot \mathrm{yr}^{-1} \text { and O\&M to ZAR250 } \text { person }^{-1} \cdot \mathrm{yr}^{-1} \text {, } \\
\text { recovery of } 2 \mathrm{~kg} \mathrm{~N}+\mathrm{P}+\mathrm{K}, 5 \mathrm{~kg} \text { organic matter for VIP }\end{array}$ \\
\hline 11 & 2.53 & 2.29 & $\begin{array}{l}\text { Socio-cultural values adjusted for resistance to on-site systems, weighting of socio- } \\
\text { cultural category increased }\end{array}$ \\
\hline
\end{tabular}


over the baseline value and the LaDePa system offers a similar increase in score for VIPs. These initiatives by EWS improve the sustainability of these on-site systems.

\section{CONCLUSIONS}

MCDA presents a number of challenges if it is to be implemented in a rigorous manner. Among these is the development of scales which reflect the value that stakeholders place on the changes in the value of a variable. This is further complicated by the differences between stakeholders. For example, whereas a sanitation service provider might consider a system that requires 5 -yearly emptying 5 times better than one which requires yearly emptying, a user might favour more frequent emptying so that the system requires a smaller vault or provides less visibility of faecal matter. In such a case, the transformation of raw scores into values for aggregation would require a completely different function.

The application of linear functions is often not appropriate but the exact nature of the best transformation to apply is difficult to ascertain. In this study, the transformations were either linear or attempted to assign values to the possible scores based on the commonly encountered raw scores. Thus, for example, the frequency of pit-emptying proposed for UDDTs in eThekwini is yearly at present, while VIPs are emptied on a 5-year cycle. Chemical toilets which are another alternative used in informal settlements require more frequent intervention while flush toilets may require very infrequent intervention at the household level. This MCDA attempted to capture these practicalities, but this scaling does not necessarily meet the stringent requirement for a ratio scale which is desirable in an MCDA.

In order to achieve a 'true valuation' of each alternative, stakeholders would be required to complete an onerous set of pairwise comparisons to ensure that the trade-offs between criteria are made. Furthermore, with the range of criteria included in this MCDA, it would be difficult for any one group of stakeholders to evaluate those trade-offs, since the three main criteria represent the interests of three different groupings: community and environmental experts (environmental criteria), municipalities (technical and financial criteria) and target communities (socio-cultural criteria).
While one of the aims of an MCDA is often to allow as many stakeholders as possible to influence the final decision through the process of the weighting of objectives, the results of this process are likely to be predictable and simply to delineate the differences of interest which exist. However, an MCDA may provide an objective framework within which participatory planning can take place, encouraging stakeholders to develop a better understanding of one another's points of view and thus leading to the compromises necessary for a truly sustainable solution.

If the engineer is looking for a definitive answer to the question 'Which option shall I implement?' then the MCDA may not provide this. However, if the question was phrased as 'What process should I follow in order to arrive at a course of action which has a better chance of success', then the MCDA may have something to offer. It poses the questions that the engineer needs to investigate before he or she makes a decision. The engineer is the 'expert' who enters the ratings for any given system and must therefore be fully informed before doing so.

A comprehensive environmental assessment should provide values for the 8 indicators required by the MCDA. In the course of this study, it became obvious that these apparently simple figures were not easy to find, particularly for on-site sanitation systems. It is also important to note that these figures are specific not only to the sanitation option being considered but also to the entire spectrum of options which accompany it, from collection to disposal, sometimes referred to as the sanitation value chain (Fig. 2) (BMGF, 2012; Tilley et al., 2008). Furthermore, the cultural practices of the target community will also influence the environmental outcomes. Even if the engineer makes some rough estimates he or she should be considerably better informed after this assessment.

The financial implications of the different options may also be less simple than at first appears. Once again, the entire sanitation value chain should be considered. WhichSan does take the costs for both technology and disposal into account and indicates both capital and maintenance costs. It was favoured for this study because it was specifically designed for the same target: South Africa municipal managers. WASHcost provides for the cost of ongoing support for sanitation systems and would be an appropriate alternative if an MCDA were to be applied in sanitation projects in a different context.

\section{SANITATION VALUE CHAIN}

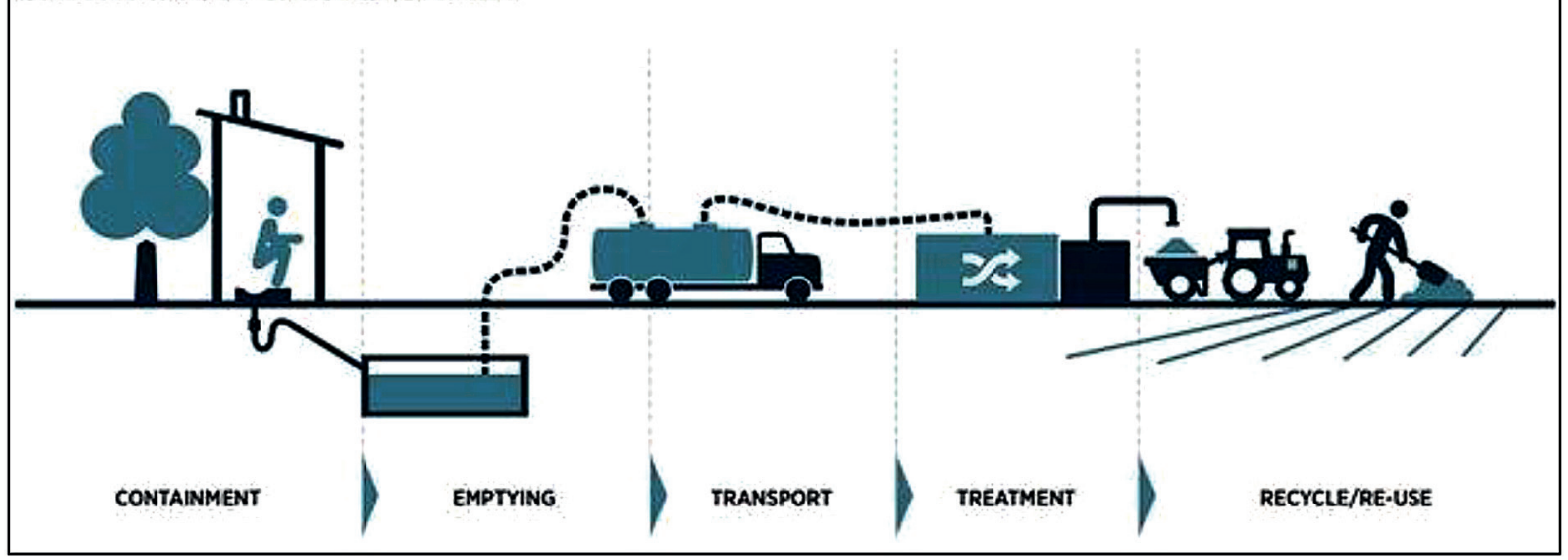


The durability, robustness and need for outside intervention have both extrinsic components attributable to the technical design and intrinsic components which depend on topography and current infrastructure (e.g. ease of access for pit emptying) and people's ability and willingness to care for and maintain the structures. This highlights another point about this type of MCDA: independence of indicators is difficult to ensure.

People's aspirations, cultural beliefs, community structures and political allegiance may all have a bearing on the success or failure of a project. The very process of investigating these may affect the outcome. It is not enough to create facilitating committees once the technical solution has already been decided. Engineers need to offer different options and to try to keep as open a mind as possible so that citizens do not feel that the consultation process is simply window-dressing. Furthermore, political support across the spectrum may be crucial to the success of a project, as the Cape Town 'toilet wars' amply demonstrated (Robins, 2014).

Difficulties were encountered when trying to meet the rigorous requirements of the academic community for weight elicitation and value function development. Further research is required to overcome the burden which would be placed on the engineer and decision makers if these requirements were to be implemented. While scenario analysis demonstrated the value of this type of MCDA for taking into account different perspectives and highlighting the range of factors which influence the sustainability of sanitation projects, other uses of indicators may be more valuable. For example, the TAF approach which does not attempt any numerical scoring and which presents a matrix of indicators for 6 sustainability dimensions and 3 stakeholder groupings could guide municipal engineers through a similar process to that advocated in this study, while retaining more detail in the final output.

\section{ACKNOWLEDGEMENTS}

The authors wish to thank Dave Wilson, Teddy Gounden and Neil Macleod of EWS for their assistance with this project.

\section{REFERENCES}

AGUDELO C, MELS A and BRAADBAART O (2007) Multi-criteria framework for the selection of urban sanitation systems. In: Proceedings of the $2^{\text {nd }}$ SWITCH Scientific Meeting, 25-29 November 2007, Tel Aviv.

ASSEFA G and FROSTELL B (2007) Social sustainability and social acceptance in technology assessment: A case study of energy technologies. Technol. Soc. 29 (1) 63-78. https://doi.org/10.1016/j. techsoc.2006.10.007

AUSTIN L (2003) Ecosan: an unsuccessful sanitation scheme at a rural school: Lessons learned from the project failure. In: Proc. 2nd International Symposium on Ecological Sanitation, 7 to 11 April 2003, Lübeck.

BAKARE B, FOXON K, BROUCKAERT C and BUCKLEY C (2012) Variation in VIP latrine sludge contents. Water SA 38 (4) 479-486. https://doi.org/10.4314/wsa.v38i4.2

BALKEMA AJ, PREISIG HA, OTTERPOHL R and LAMBERT FJ (2002) Indicators for the sustainability assessment of wastewater treatment systems. Urban Water 4 (2) 153-161. https://doi. org/10.1016/S1462-0758(02)00014-6

BELTON V and STEWART T (2002) Multiple Criteria Decision Analysis: An Integrated Approach. Kluwer Academic Publishers, Boston. https://doi.org/10.1007/978-1-4615-1495-4

BMGF (Bill \& Melinda Gates Foundation) (2012) Water, sanitation and hygiene: strategy review. Bill and Melinda Gates Foundation, Seattle.

BHAGWAN J, STILL D, BUCKLEY C and FOXON K (2008)
Challenges with up-scaling dry sanitation technologies. Water Sci. Technol. 58 (1) 21-27. https://doi.org/10.2166/wst.2008.606

BRACKEN P, KVARNSTRÖM E, YSUNZA A, KÄRRMAN E, FINNSON A and SAYWELL D (2005) Making sustainable choices-the development and use of sustainability oriented criteria in sanitary decision making. Third International Conference on Ecological Sanitation, 23-26 May, 2005, Durban, South Africa.

BROUCKAERT C, FOXON K and WOOD K (2013) Modelling the filling rate of pit latrines. Water SA 39 (4) 555-562. https://doi. org/10.4314/wsa.v39i4.15

BUCHHOLZ T, LUZADIS VA and VOLK TA (2009) Sustainability criteria for bioenergy systems: results from an expert survey. $J$. Clean. Prod. 17 (Supplement 1) S86-S98. https://doi.org/10.1016/j. jclepro.2009.04.015

BUCKLEY C, FOXON K, BROUCKAERT C, RODDA N, NWANERI C, BALBONI E, COUDERC A and MAGAGNA D (2008) Scientific support for the design and operation of ventilated improved pit latrines (VIPs) and the efficacy of pit latrine additives. WRC Report No. TT 357/08. Water Research Commission, Pretoria.

BUCKLEY C, FOXON K, RODDA N, BROUCKAERT C, MANTOVANELLI S and MNGUNI M (2008) Research into urine diversion, ventilated improved double pit toilets (UD/VIDP) in eThekwini. Part A: Physical and health-related characteristics of UD/VIDP vault contents. WRC Report No. 1629/1/08. Water Research Commission, Pretoria.

COTTON A and SAYWELL D (1998) On-Plot Sanitation in LowIncome Urban Communities: Guidelines for Selection. WEDC, Loughborough University, London.

DE SILVA NK (2007) Multi-criteria analysis of options for urban sanitation and urban agriculture - case study in Accra (Ghana) and in Lima (Peru). MSc thesis, UNESCO-IHE Institute for Water Education.

DEMPSEY N, BRAMLEY G, POWER S and BROWN C (2011) The social dimension of sustainable development: Defining urban social sustainability. Sustainable Dev. 19 (5) 289-300. https://doi. org/10.1002/sd.417

DICKINSON N and FONSECA C (2014) Multilingual tools to collect, analyse and use life-cycle costs of water and sanitation services, The Hague, Netherlands. URL: https://www.ircwash.org/sites/default/ files/multilingual_tools_to_collect_analyse_and_use_lcc_of_ wash_services.pdf (Accessed 3 April 2018).

DREIBELBIS R, WINCH PJ, LEONTSINI E, HULLAND KR, RAM PK, UNICOMB L and LUBY SP (2013) The integrated behavioural model for water, sanitation, and hygiene: a systematic review of behavioural models and a framework for designing and evaluating behaviour change interventions in infrastructurerestricted settings. BMC Public Health 13 (1) 1015. https://doi. org/10.1186/1471-2458-13-1015

DUNCKER L, MATSEBE G and AUSTIN L (2006) Use and acceptance of urine-diversion sanitation systems in South Africa. WRC Report No. 1439/2/06. Water Research Commission, Pretoria.

DWA (Department of Water Affairs, South Africa) (2012) Report on the status of sanitation services in South Africa. Department of Water Affairs, Pretoria.

DWAF (Department of Water Affairs and Forestry, South Africa) (1996) National Sanitation Policy - White Paper. Department of Water Affairs and Forestry, Pretoria.

DWAF (Department of Water Affairs and Forestry, South Africa) (2003) Strategic Framework for Water Services: Water is Life, Sanitation is Dignity. Department of Water Affairs and Forestry, Pretoria.

DWIPAYANTI NMU, PHUNG TD, RUTHERFORD S and CHU C (2017) Towards sustained sanitation services: a review of existing frameworks and an alternative framework combining ecological and sanitation life stage approaches. J. Water Sanit. Hyg. Dev. 7 (1) 25-42. https://doi.org/10.2166/washdev.2017.086

EDWARDS W and NEWMAN JR (1982) Multiattribute Evaluation (Quantitative Applications in the Social Sciences). Sage, Beverly Hills, USA.

FINNEY BA and GEARHART RA (2004) A user's manual for WAWTTAR. Humboldt State University, Arcata, CA. URL: http://firehole.humboldt. edu/wawttar/download.html (Accessed 15 June 2016). 
FLORES A, BUCKLEY C and FENNER R (2008) Selecting wastewater systems for sustainability in developing countries. $11^{\text {th }}$ International Conference on Urban Drainage, 31 August to 5 September 2008, Edinburgh.

FRANCEYS R, PICKFORD J and REED R (1992) A guide to the development of on-site sanitation. World Health Organization, Geneva. URL: http://www.who.int/water_sanitation_health/ hygiene/envsan /onsitesan.pdf (Accessed 11 April 2015).

GOUNDEN T and BUCKLEY C (2009) Ethekwini Municipality challenges with the implementation and up-scaling of UDDTs. SuSanA Seminar, 8 November 2009, Johannesburg.

GOUNDEN T, PFAFF B, MACLEOD N and BUCKLEY C (2006) Provision of free sustainable basic sanitation: the Durban experience. 32 $2^{\text {nd }}$ WEDC International Conference, 13 to 17 November 2006, Colombo.

HAJKOWICZ S and HIGGINS A (2008) A comparison of multiple criteria analysis techniques for water resource management. Eur. J. Oper. Res. 184 (1) 255-265. https://doi.org/10.1016/j. ejor.2006.10.045

HARRISON J and WILSON D (2012) Towards sustainable pit latrine management through LaDePa. Sustainable Sanit. Pract. 13 25-32.

HELLSTRÖM D, JEPPSSON U and KÄRRMAN E (2000) A framework for systems analysis of sustainable urban water management. Environ. Impact Assess. Rev. 20 (3) 311-321. https:// doi.org/10.1016/S0195-9255(00)00043-3

HOLDEN R, TERREBLANCHE R and MULLER M (2003) Factors which have influenced the acceptance of EcoSan in South Africa and development of a marketing strategy. In: Proc. $2^{\text {nd }}$ International Symposium on Ecological Sanitation, 7 to 11 April 2003, Lübeck.

HOWARD J, QUINN N, EALES K and VOLLER R (2000) The development of an on-site sanitation planning and reporting aid (SSPRA) for selection of appropriate sanitation technologies for developing communities. WRC Report No. 586/1/00. Water Research Commission, Pretoria.

HUTTON G and HALLER L (2004) Evaluation of the costs and benefits of water and sanitation improvements at the global level. World Health Organization, Geneva.

KATUKIZA A, RONTELTAP M, OLEJA A, NIWAGABA C, KANSIIME F and LENS P (2010) Selection of sustainable sanitation technologies for urban slums-A case of Bwaise III in Kampala, Uganda. Sci. Total Environ. 409 (1) 52-62. https://doi.org/10.1016/j. scitotenv.2010.09.032.

KIMERA P, SMET J, OLSCHEWSKI A and PARKER A (2013) Context-specific validation and introduction of technologies for sustainable WASH services. $36^{\text {th }}$ WEDC International Conference: Delivering Water, Sanitation and Hygiene Services In An Uncertain Environment, 1 to 5 July 2013, Nakuru.

LOETSCHER T (1999) Appropriate sanitation in developing countries: the development of a computerised decision aid. $\mathrm{PhD}$ thesis, University of Queensland.

LUTCHMINARAYAN RD, KNIGHT SE, ESTERHUIZEN T and STENSTROM TA (2007) A comparative study evaluating health outcomes of sanitation, water services and hygiene education in eThekwini district, Durban, South Africa. International Conference on Sustainable Sanitation, 26 to 29 August 2007, Dongsheng.

MAHARAJ N (2012) Governance and service delivery: a case-study of sanitation in Inanda, Durban. PhD thesis, University of KwaZulu-Natal.

MONTGOMERY MA, BARTRAM J and ELIMELECH M (2009) Increasing functional sustainability of water and sanitation supplies in rural sub-Saharan Africa. Environ. Eng. Sci. 26 (5) 1017-1023. https://doi.org/10.1089/ees.2008.0388

MUGA HE and MIHELCIC JR (2008) Sustainability of wastewater treatment technologies. J. Environ. Manage. 88 (3) 437-447. https:// doi.org/10.1016/j.jenvman.2007.03.008

MUKULUKE J and NGIRANE-KATASHAYA G (2006) Exploring sustainability of sanitation systems: Social-cultural acceptability analysis of technology options for Kampala's peri-urban areas using multi-criteria decision analysis. J. Eng. Appl. Sci. 1 (4) 445-455.

MURPHY K (2012) The social pillar of sustainable development: a literature review and framework for policy analysis. Sustainability: Sci. Pract. Polic. 8 (1). https://doi.org/10.1080/15487733.2012.11908081
NARSAI P, TAYLOR M, JINABHAI C and STEVENS F (2013) Variations in housing satisfaction and health status in four lower socio-economic housing typologies in the eThekwini Municipality in KwaZulu-Natal. Dev. South. Afr. 30 (3) 367-385. https://doi.org/1 0.1080/0376835X.2013.817304

NWANERI CF (2009) Physico-chemical characteristics and biodegradability of contents of ventilated improved pit latrines (VIPs) in eThekwini Municipality. MSc thesis, University of KwaZulu-Natal.

OLSCHEWSKI A and CASEY V (2015) The technology applicability framework. a participatory tool to validate water, sanitation, and hygiene technologies for low-income urban areas. In: Hostettler S, Hazboun E and Bolay J (eds) Technologies for Development. Springer, Berlin. https://doi.org/10.1007/978-3-319-16247-8_18.

PALANIAPPAN M, GLEICK PH and CHANGE E (2008) A review of decision-making support tools in the water, sanitation, and hygiene sector. Pacific Institute, Oakland, California.

PALME U, LUNDIN M, TILLMAN A-M and MOLANDER S (2005) Sustainable development indicators for wastewater systemsresearchers and indicator users in a co-operative case study. Resour. Conserv. Recycl. 43 (3) 293-311. https://doi.org/10.1016/j. resconrec.2004.06.006

PANESAR A and WERNER C (2006) Overview of the global development of EcoSan. In: Proc. DWA/BMZ/GTZ Conference, 25 to 26 October 2006, Eschborn.

ROBINS S (2014) The 2011 toilet wars in South Africa: Justice and transition between the exceptional and the everyday after Apartheid. Dev. Change 45 (3) 479-501. https://doi.org/10.1111/ dech.12091

ROMA E, PHILP K, BUCKLEY C, XULU S and SCOTT D (2013) User perceptions of urine diversion dehydration toilets: Experiences from a cross-sectional study in eThekwini Municipality. Water SA 39 (2) 302-312. https://doi.org/10.4314/wsa.v39i2.15

ROSEMARIN A (2008) Pathways for Sustainable Sanitation: Achieving the Millennium Development Goals. IWA Publishing, Stockholm.

RSA (Republic of South Africa) (1997) Water Services Act. Act No. 108 of 1997. Government Gazette No. 18522. Government Printer, Cape Town.

SALISBURY F (2015) An investigation into the application of multiple criteria decision analysis as a decision support tool for municipal engineers. MSc thesis, University of KwaZulu-Natal.

STARKL M, BRUNNER N and STENSTRÖM T-A (2013) Why do water and sanitation systems for the poor still fail? Policy analysis in economically advanced developing countries. Environ. Sci. Technol. 47 (12) 6102-6110. https://doi.org/10.1021/es3048416

STEWART TJ, FRENCH S and RIOS J (2013) Integrating multicriteria decision analysis and scenario planning-Review and extension. Omega 41 (4) 679-688. https://doi.org/10.1016/j.omega.2012.09.003

STILL D and FOXON K (2012) Tackling the challenges of full pit latrines, Volume 1: Understanding sludge accumulation in VIPs and strategies for emptying full pits. WRC Report No. 1745/2/12. Water Research Commission, Pretoria.

STILL D, WALKER N and HAZELTON D (2009) Basic Sanitation Services in South Africa: Learning from the past, planning for the future. WRC Report No. TT 414/09. Water Research Commission, Pretoria.

STRAUSS M and MONTANGERO A (2002) FS management - review of practices, problems and initiatives. DFID/GHK, Dübendorf.

TAYLOR S, ASIMAH S, BUAMAH R, NYARKO K, SEKUMA S, COULIBALY Y, WOZUAME A, JEFFREY P and PARKER A (2017) Towards sustainable water, sanitation and hygiene technology use in sub-Saharan Africa: the Learning Alliance approach. Water Polic. 19 (1) 69-85. https://doi.org/10.2166/wp.2016.252

TILLEY E, LÜTHI C, MOREL A, ZURBRÜGG C and SCHERTENLEIB R (2008) Compendium of Sanitation Systems and Technologies. Swiss Federal Institute of Aquatic Science and Technology (Eawag), Dübendorf.

VAN DER VLEUTEN-BALKEMA AJ (2003) Sustainable wastewater treatment: developing a methodology and selecting promising systems. PhD thesis, Technische Universiteit Eindhoven.

VAN LIER J, ZEEMAN G, VAN BUUREN J and LETTINGA G (2000) Decentralised Sanitation Concepts: Perspectives for Reclamation of Domestic Sewage for Agricultural Production by using Low-Cost

http://dx.doi.org/10.4314/wsa.v44i3.12

Available on website http://www.wrc.org.za

ISSN 1816-7950 (Online) = Water SA Vol. 44 No. 3 July 2018

Published under a Creative Commons Attribution Licence 
Treatment Technologies. EP \& RC Foundation, Wageningen.

VELKUSHANOVA K (2013) Properties of faecal sludge from on-site sanitation facilities in Durban, South Africa. IWA Development Congress, 14 to 17 October 2013, Nairobi.

VON MÜNCH E (2007) A report evaluating various ecosan system alternatives for urban areas by multi criteria analysis-using Accra, Ghana as a case study. UNESCO-IHE, Delft, Netherlands.

WAGNER EG and LANOIX JN (1958) Excreta disposal for rural areas and small communities. WHO Monograph Series. World Health Organization, Geneva.
WIWE S (2005) Participatory multi-criteria decision making in sanitation planning in Ecuador. MSc thesis, Technical University of Denmark.

ZURBRÜGG C and TILLEY E (2009) A system perspective in

sanitation - human waste from cradle to grave and reincarnation. Desalination 248 (1) 410-417. https://doi.org/10.1016/j.

desal.2008.05.082 